\title{
Evaluation of Physical Activity in a Group of Physically Inactive Individuals from a Government Corporation
}

\author{
Denise Castro de Souza Côrtes*1, 0ziel Marcio Araújo Tardin ${ }^{1}$, Ana Carolina Castro Côrtes², Monique \\ Christiane Braga Gomes ${ }^{1}$, Adriana Alvarez Arantes ${ }^{1}$ and Ana Paula Pimentel Mendonça ${ }^{1}$ \\ ${ }^{1}$ Pró-Cardíaco Hospital - Rio de Janeiro, Fundation of Assistance and Social Security of BNDES - FAPES, Brazil \\ ${ }^{2}$ Universidade Federal Fluminense - UFF Undergraduate, Brazil
}

*Corresponding author: Denise Castro de Souza Côrtes, Pró-Cardíaco Hospital - Rio de Janeiro, Fundation of Assistance and Social

Security of BNDES - FAPES, Brazil

\section{ARTICLE INFO}

Received: 幽 February 22, 2019

Published: 幽 March 11, 2019

Citation: Denise Castro de Souza C, Oziel Marcio Araújo T, Ana Carolina Castro C, Monique Christiane Braga G, Adriana Alvarez A, Ana Paula Pimentel M. Nucleotide Variations in microRNA-Binding Sites: The Need of Novel Tools for the Nucleic Acid Alignment (MicroRNA-binding Sites Variations and Computerized Approaches). Biomed J Sci \& Tech Res 15(4)-2019. BJSTR. MS.ID.002747.

Abbreviations: IPAQ: International Physical Activity Questionnaire; WHO: World Health Organization; CDC: Centers for Disease Control; CSA: Computer Science \& Applications

\begin{abstract}
Modern societies are undergoing considerable changes, such as the increase of physical inactivity. Epidemiological and scientific studies report that physical activity is related to reduced morbidity and mortality from a number of diseases. It is not easy to assess and quantify the degree of physical activity of individuals, as the instruments used do not always meet all the requirements of the activity performed and there is no gold standard established. This study aims to compare two methods of evaluating the usual or daily physical activity done by the employees from a government corporation, who self-reported being physically inactive. The study included 41 volunteers, of which $65.9 \%$ were males, with a mean age of $46 \pm 9.8$ years, from a government corporation based in Rio de Janeiro.

The instruments used were a pedometer and the International Physical Activity Questionnaire (IPAQ). The study found $34.0 \%$ of physically inactive and little active individuals classified by a pedometer and $26.5 \%$ of physically inactive individuals and irregularly active type B individuals according to IPAQ. The two methods were compared with each other for the correlation of physical activity classification, and similarity was found in only six participants with $17.6 \%$ concordance degree, revealing discrepancy between the methods (Kappa coefficient: -0.030). In this sample, it was found that $66 \%$ of individuals self-reported as physically inactive were reclassified as non-physically inactive when the pedometer was used and $73.5 \%$ when the IPAQ was used, based on the activities performed in their daily routine.
\end{abstract}

Keywords: Physical Activity; Sedentarism; Health Promotion

\section{Introduction}

Modern societies are facing considerable changes, such as the increase of physical inactivity [1]. The study on Sports Practice and Physical Activity conducted by IBGE in 2015 found that $70.0 \%$ of Brazilians older than 15 years of age are physically inactive [2] and data from the Ministry of Sports, in 2013, reveal that $45.9 \%$ or 67 million Brazilians are physically inactive [3]. The World Health Organization (WHO) states that physical inactivity is the fourth leading risk factor for death in the world and data from 2014 place it as responsible for about 3.2 million deaths each year [4].
In 2008, the Department of Health and Human Services created the first physical activity guide for Americans, advising on the degree of exercise required to derive health benefits. Data from 2013 reveal that 3 out of 10 individuals reported being physically inactive in their leisure time and only half reported engaging in physical activity consistently [5]. Berlin apud Guedes points out that cardiovascular diseases are 1.9 times more prevalent in less physically active individuals than in physically active individuals [6]. Epidemiological and scientific studies show that the practice of 
physical activity is related to reduced morbidity and mortality from a number of diseases [1-7].

Actions intended to fight physical inactivity have been encouraged in the general population, with at least a few recommendations to promote health benefits, consisting in one of the main public health measures [3-7]. The World Health Organization8 recommends, for children and adolescents aged 5-17, 60 minutes of moderate to vigorous physical activity on a daily basis; and for adults from 18 years of age, 150 minutes of moderate aerobic activity per week or 75 minutes of vigorous aerobic activity, as well as bodybuilding exercises for large muscle groups at least twice a week [1-8]. Physical activity consists of any body movement performed by the skeletal muscles that results in energy expenditure. This fact poses difficulties to the overall physical evaluation of the individuals, since everyday activities like leisure, general walking activities and even occupational activities contribute to energy expenditure, including the individual's body mass index. To evaluate the influence of exercise on health promotion, objective and/or subjective methods are required to quantify the practice of physical activity in the population in order to find out the results of interventions in this area [1-7]. The instruments used for evaluating physical activity do not often include all the variables involved in this action: duration, frequency and intensity of the physical activity performed.

Many instruments are different from each other in the aspects they evaluate. They can be more or less recommended, depending on the characteristics of the group being studied, such as: age, sex and cultural aspects. There is no gold standard method to measure physical activity, but doubly labeled water is considered as such, because it measures the energy expenditure of the activities performed and is used in scientific research studies (Table 1). In this study it was decided to use two concomitant methods: an objective one - Pedometer - and a subjective one - short version of the International Questionnaire of Physical Activity (IPAQ) to evaluate the physical activity of the individuals. The pedometer is an instrument that represents the class of motion sensors. It counts the number of daily steps taken by an individual and some brands inform the distance covered and the energy expenditure generated by the number of steps. The main disadvantages of this method include the inability to evaluate the intensity of the activity performed, such as distinguishing between walking and running, and it does not record other activities that may result in energy expenditure, such as walking and carrying heavy items at the same time.

Table 1: Characteristics of physical activity evaluation methods.

\begin{tabular}{|c|c|c|c|c|c|}
\hline \multicolumn{7}{|c|}{ Characteristics of Physical Activity Evaluation methods } \\
\hline Methods & Factors Measured & Frequency & Intensity & Duration & Energy expenditure \\
\hline Labeled water & C02 Production & No & No & Yes & Yes \\
\hline Indirect Calorimetry & O2 Consumption & Yes & Yes & Yes & Yes \\
\hline Cardiac Monitor & Beats/min & Yes & Yes & Yes & Yes \\
\hline Motion Sensors & Motion & Yes & Yes & Yes & Yes \\
\hline Direct Observation & Activity & Yes & No & Yes & Yes \\
\hline Pedometers & Steps & No & Yes & Yes &
\end{tabular}

Source: Welk apud Cafruni [1].

The Questionnaires represent information provided by the individuals' routine of physical activities within a certain period of time, informing the type, frequency and intensity of the activity. The main disadvantages of the method include the lack of precision to measure the physical activity, and the individual's difficulty of understanding the measurement of the activity, especially smaller children. The intention to use a single comparable instrument in several countries led to the creation of the International Physical Activity Questionnaire (IPAQ) by the WHO, together with the United States' Centers for Disease Control and Prevention (CDC) and the Karolinska Institute in Sweden [7]. It allows to evaluate the weekly time spent on activities, divided into light, moderate and vigorous intensity, with minimum duration of 10 minutes and separated into four categories: work, transport, domestic activities and leisure. It has three types of versions: the long one with 27 questions, a short one with 7 questions and the adapted version with 15 questions, which is used in special groups such as the elderly, children and obese individuals [9-10]. The IPAQ was validated in populations in Brazil [7-11]. Although the IPAQ is widely used in the world literature, the literature points out that this method tends to overestimate the amount of physical activity undertaken. It is thus recommended to compare it with some objective method, such as pedometer or accelerometer.

\section{Material and Method}

This prospective study aims to compare two methods of evaluating usual or daily physical activity of employees from a government corporation, who self-reported being physically inactive. Started in the end of 2016, the study has evaluated, to date, 41 volunteers, of which $65.9 \%$ were males, with mean age of $46 \pm 9.8$ years. Two instruments were used: the pedometer and the International Physical Activity Questionnaire - IPAQ (short version) 
to characterize informal physical activity. The descriptive analysis is presented as a table with the data expressed by the mean, standard deviation, median, interquartile range, minimum and maximum for numerical data and by the frequency and percentage for categorical data. The inferential analysis used the Kappa coefficient for the concordance of classification between the instruments. For the association between the factors measured by the instruments (number of steps and time of exercise), Spearman's coefficient was used. A non-parametric method was applied, as the numerical variables did not present normal distribution due to rejection of normality by the Shapiro-Wilks test. The criterion for determining significance was the level of $5 \%$. The statistical analysis was processed using the software SAS System, version 6.11.

\section{Results}

A median of 8680 steps/day and daily exercise time of 24 minutes or 164 minutes/week in the study population were obtained (Table 2). A total of $34.0 \%$ of physically inactive and little active individuals classified by pedometer and $26.5 \%$ of physically inactive and irregularly active type B individuals classified by the IPAQ were found (Table 3). The two methods were analyzed for correlation between each other, considering the classification of the physical activity. Similarity was found in six participants, with a concordance degree of $17.6 \%$, showing discrepancy between the methods (Kappa coefficient - 0.030) (Figure 1).

Table 2: Characterization of the study population (numerical variables).

\begin{tabular}{|c|c|c|c|c|c|c|c|c|c|}
\hline \multicolumn{7}{|c|}{ Characterization of the Study Population (Numerical Variables) } \\
\hline Variables & n & Mean & SD & Median & IR & & Minimum & Maximum \\
\hline Age (years) & 41 & 46.1 & 9.8 & 48.0 & 36 & - & 54 & 29 & 61 \\
\hline BMI (Kg/m $)$ & 41 & 29.9 & 5.5 & 29.2 & 25.8 & - & 33.8 & 20 & 42.5 \\
\hline No. Steps/Day & 41 & 8842 & 3906 & 8680 & 6138 & - & 10797 & 1445 & 21163 \\
\hline Time of Exercise/Week (Min) & 34 & 493 & 599 & 168 & 93 & - & 660 & 0 & 2250 \\
\hline Time of Exercise/Day (Min) & 34 & 70 & 86 & 24 & 13 & - & 94 & 0 & 321 \\
\hline
\end{tabular}

Key: SD-standard deviation; IR- interquartile range (R1-R3); BMI-body mass index.

Table 3: Characteristics of the study population (categorical variables).

\begin{tabular}{|c|c|c|c|}
\hline \multicolumn{4}{|c|}{ Characteristics of the Study Population (Categorical Variables) } \\
\hline Variables & Category & $\mathbf{n}$ & $\%$ \\
\hline \multirow{2}{*}{ Sex } & male & 27 & 65.9 \\
\hline & female & 14 & 34.1 \\
\hline \multirow{2}{*}{ Age $>50$ years } & yes & 16 & 39.0 \\
\hline & no & 25 & 61.0 \\
\hline \multirow{2}{*}{ Obese } & yes & 20 & 48.8 \\
\hline & no & 21 & 51.2 \\
\hline \multirow{5}{*}{ Pedometer Classification (Original) } & physically inactive & 5 & 12.2 \\
\hline & little active & 13 & 31.7 \\
\hline & moderately active & 12 & 29.3 \\
\hline & active & 6 & 14.6 \\
\hline & very active & 5 & 12.2 \\
\hline \multirow{5}{*}{ IPAQ Classification (Original) } & physically inactive & 3 & 8.8 \\
\hline & Irregularly active type B & 6 & 17.6 \\
\hline & Irregularly active type A & 4 & 11.8 \\
\hline & active & 17 & 50.0 \\
\hline & very active & 4 & 11.8 \\
\hline
\end{tabular}

Key: IPAQ - International Questionnaire on Physical Activity (short version). 


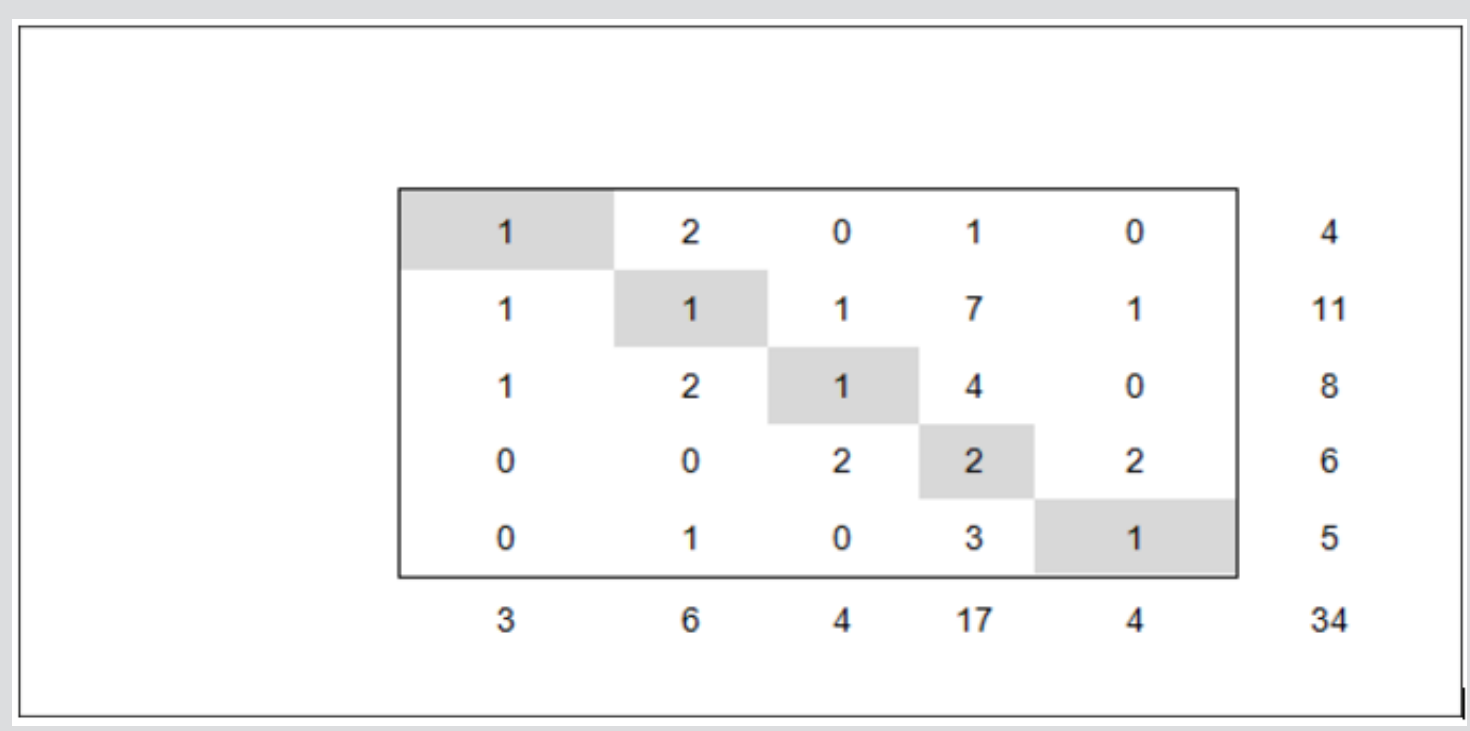

Figure 1: Correlation between the instruments used: Pedometer vs. IPAQ.

Key: IPAQ - International Physical Activity Questionnaire

\section{Discussion}

When we specifically analyzed the individuals reported as being physically inactive, as they do not perform any type of conventional physical activity, it was found that many could be reclassified as not physically inactive if we consider the daily routine activities performed. The objective methods seem to have a greater sensitivity for evaluation and quantification of the activity performed. The pedometer is a practical easy-to-use instrument that can be used by any individual to quantify a basic activity that is the act of walking. In this study, $66.0 \%$ of the study population was classified as not physically active. Taking 10,000 steps per day is the requirement for being considered a physically active person. The IPAQ, which represents the subjective methods, with international validation, found $26.5 \%$ of physically active individuals and very little active individuals. This percentage is very close to the $25.0 \%$ found by Côrtes [12] in a previous study that evaluated a population of 674 employees from the same company and found the presence of a physically inactive lifestyle with the application of the same instrument.

Other studies that also used the IPAQ in association with another objective physical activity evaluation method, Computer Science \& Applications (CSA) motion sensors reported a low correlation between the instruments using Spearman's correlation of 0.24 , as well as other studies reported a moderate Pearson correlation of 0.37 [13-14]. This study found no concordance between the methods regarding the classification of physical activity by the Kappa coefficient (-0.30) and no association between the number of steps and the exercise time evaluated by the Spearman's correlation coefficient ( $\mathrm{rs}=0.23$ ). The Brazilian Society of Cardiology, in the 1st Brazilian Guidelines on Cardiovascular Prevention,14 advises that although there are health benefits from activities of relatively low intensity, such as daily activities or usual or informal physical activity, it is best to practice physical exercises regularly (formal activities), following the previously mentioned recommendations, to obtain an optimal dose of regular physical activity.

\section{Conclusion}

The methods of evaluation of physical activity differ among themselves and should be used together, to better estimate the individuals' degree of informal or daily activity.

\section{Acknowledgement}

To all the medical and nursing staff of the EDSERJ outpatient clinic for their support, referring the volunteers to take part in the study.

\section{References}

1. Cafruni CB, Valadão RCD, Mello EDM (2012) Como avaliar a atividade física? Rev Bras Cienc Saúde 10(33): 61-71.

2. Oliveira N (2017) IBGE: 100 milhões de pessoas com 15 anos ou mais não praticam esporte no Brasil. Agencia Bracil.

3. Ministério do Esporte (2015) A prática de esporte no Brasil. Diagnóstico Nacional do Esporte.

4. Organização Mundial da Saúde (2014) Atividade Física. Folha Informativa no pp. 385 .

5. (2015) US Department of Health \& Human Services. Step It Up! The surgeon general's call to action to promote walking and walkable communities. Surgeon General Gov.

6. Guedes DP, Lopes CC, Guedes JEPR (2005) Reprodutibilidade e validade do questionário de atividade física em adolescentes. Rev Bras Med Esporte 11(2): 151-158.

7. Vespasiano BS, Dias R, Correa DA (2012) A utiliza o do questionário internacional de atividade física (IPAQ) como ferramenta diagnóstica do nível de aptidão física: uma revisão no Brasil. Saúde em Revista 12(32): 49-54. 
8. (2017) Global recommendations on physical activity for health. World Health Organization.

9. Mazo GZ, Benedetti TRB (2010) Adaptação do questionário internacional de atividade física para idosos. Rev Bras Cineantropom Desempenho Hum 12(6): 480-484.

10. Pardini R, Matsudo S, Araújo T, Matsudo V, Andrade E, et al. (2001) Validação do questionário internacional de nível de atividade física (IPAQ- versão 6): estudo piloto em adultos jovens brasileiros. Rev Bras Cienc Movimento 9(3): 45-51.

11. Matsudo S, Araújo T, Matsudo V, Andrade D, Andrade E, et al. (2001) Questionário internacional de atividade física IPAQ: estudo de validade e reprodutibilidade no Brasil. Rev Bras Ativ Fis Saúde 6(2): 5-18.

\section{ISSN: 2574-1241}

DOI: 10.26717/BJSTR.2019.15.002748

Denise Castro de Souza Côrtes. Biomed J Sci \& Tech Res

cC) This work is licensed under Creative Commons Attribution 4.0 License

Submission Link: https://biomedres.us/submit-manuscript.php
12. Côrtes DCS, Paula R, Mendonça APP, Arantes AA, Marandino R, Cruz RO et al. (2010) Sedentarismo em população específica de funcionários de uma empresa pública. Rev Soc Bras Clin Med 8(5): 375-377.

13. Alves MAS, Bueno FR, Haraguchi LIH, Côrrea FR, Dourado VZ (2013) Correlação entre média do número de passos diário e o teste de caminhada de seis minutos em adultos e idosos assintomáticos. Fisioter Pesqui 20(2): 123-129.

14. Simão AF, Precoma DB, Andrade JP, Correa Filho H, Saraiva JFK, et al. (2013) Sociedade Brasileira de Cardiologia. I Diretriz brasileira de prevenção cardiovascular. Arq Bras Cardiol 101(6 supl 2): 1-63.

$\begin{array}{ll}\text { BIOMEDICAL } & \text { Assets of Publishing with us } \\ \text { RESEARCHES } & \text { - Global archiving of articles } \\ & \text { - Immediate, unrestricted online access } \\ & \text { - Rigorous Peer Review Process } \\ \end{array}$

